\title{
Affordability Challenges Drive Food Insufficiency in the Pandemic
}

Jessica A. Carson and Sarah Boege

Note: Due to an erratum notice released June 17, 2020 by the U.S. Census Bureau regarding their incorrectly reported food insufficiency data, this snapshot replaces a previous Carsey publication with the correct and updated data.

A new survey from the U.S. Census Bureau finds that between June 4 and June 9, 10 percent of adults faced food insufficiency, reporting that they "sometimes" or "often" did not have enough to eat in the past seven days. When asked why they did not have enough food, 79.2 percent said that they could not afford to buy more. About 15 percent cited access challenges, including being afraid or unwilling to go out, or unable to get out to buy more food (including because of health or transportation challenges). A considerable share of adults without enough food expected the circumstance would be enduring, with 43.7 percent reporting they were not at all confident that they'd be able to afford food in the next four weeks.

These findings show that affordability is the key driver of food insufficiency during the pandemic, a pattern that has persisted across weeks (data not shown). Affordability barriers indicate that bolstering household food spending resources is crucial, either with general supports (like unemployment insurance or housing assistance) that free up money for food or food-specific resources like expanded SNAP benefits. Enhancing the reach and capacity of food banks and food pantries that are filling essential gaps remains important amid persistent pandemic challenges.

\section{REASON(S) FOR FOOD INSUFFICIENCY AMONG ADULTS EXPERIENCING FOOD INSUFFICIENCY, JUNE 4-JUNE 9}

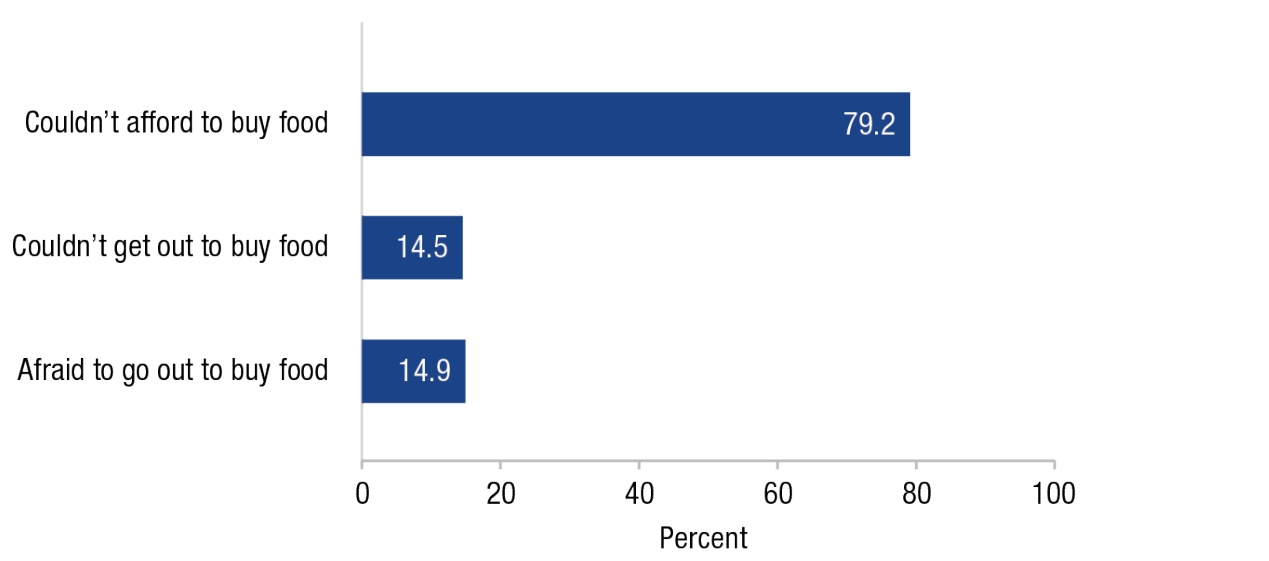



Getting food is a problem for people experiencing food insufficiency during the pandemic, but affording food is the biggest challenge.

\section{About the Authors \\ Jess Carson is a research assistant professor with the Vulnerable Families Research Program at the Carsey School of Public Policy.}

Sarah Boege is a policy analyst with both the Vulnerable Families Research Program and the Center for Impact Finance at the Carsey School of Public Policy.

See Related Publications at carsey.unh.edu

- Innovation in Food Access Amid the COVID-19 Pandemic (May 2020) 